\title{
LA BIBLIOTECA DE MELCHOR DE MACANAZ. AUTORES Y FUENTES FORALES
}

\author{
María Dolores GARCIA GOMEZ \\ Universidad de Alicante
}

Si bien la primera intención al abordar el estudio de la biblioteca de Melchor de Macanaz era la de acercarnos desde su raíz cultural a las actuaciones políticas de este controvertido personaje, valiéndonos del conocimiento pormenorizado de todos sus libros, a lo largo del trabajo, y como consecuencia de ese planteamiento inicial, algunos objetivos se han añadido al primer comentario bibliográfico.

El estudio de las bibliotecas constituye sin duda la más sólida fuente para el conocimiento y explicación de factores culturales o sociales: es ése un camino apenas iniciado y cuyos resultados globales desvelarán sin duda importantes facetas históricas. No siempre parece, sin embargo, que pueda ser norma el adivinar, proyectar o aplicar a través de un conjunto de libros la personalidad humana o el ideario político de un personaje. Pero sí habrá ocasiones en las que las palabras de Marañón... "los libros que cada cual escoge para su recreo, para su instrucción, incluso para su vanidad, son verdaderas huellas dactilares de su espíritu..." I sean un claro resumen del caso como el que nos ha ocupado este trabajo.

Hemos llevado a cabo el estudio bibliográfico de la biblioteca de Melchor de Macanaz ${ }^{2}$, a partir del inventario inquisitorial que se realizó tras su huida a Francia, siendo fiscal general de Felipe V, por orden de apresamiento de la Inquisición, y, además de ocuparnos desde un punto de vista jurídico de dicha librería, primera y única intención al comenzar este estudio, tras finalizarlo han surgido, como decimos, otras valoraciones: por una parte se nos presenta como ejemplo de una biblioteca de trabajo, y desde tal punto de vista se refiere a ella el mismo Macanaz ${ }^{3}$. Por tratarse además de una biblioteca inventarial y no testamental, pueden estar limitadas sus conclusiones generales, debido a la interrupción brusca en su evolución, que de otra forma habrían introducido nuevos elementos impuestos por la edad y otros gustos,

1 MARAÑON G.: "La biblioteca del Conde-Duque" B.R.A.H. 1937, t. 107 pp. 673-677.

2 GARCIA GOMEZ, M." Dolores : "La biblioteca jurídica de Melchor de Macanaz". Inédito.

3 MALDONADO MACANAZ, J.: Testamento Político. Pedimento Fiscal. Ediciones del Instituto de Estudios Políticos. Madrid, 1972, p. 137. 
pero, sin embargo, se enriquece el contenido con la homogeneidad que le da su carácter de instrumento de trabajo, que responde a los años de intensa actividad política $\sin$ apenas reflejo de las mixtificaciones que impone el tiempo.

Como consecuencia de esta particularidad se identifican claramente los libros que se ocupan de las actuaciones políticas que caracterizan a Macanaz: su regalismo y la obstinación por erradicar los privilegios feudales.

Nos hemos ocupado de su formación regalista y de la extensa muestra de autores regalistas hispanos de la biblioteca en el trabajo "La biblioteca de Melchor de Macanaz. Fuentes regalistas" " 4 y queremos ahora ocuparnos de la abundantísima muestra de documentos forales y autores dedicados a los mismos.

El interés por el conocimiento de los privilegios regionales no eran sino una faceta de su ideología de apoyatura real. La rebeldía de aragoneses, valencianos y catalanes, que en la Guerra de Sucesión tan violentamente se había manifestado contra Felipe V, tenía su respaldo legal en los fueros, y de ellos, los aragoneses despertaban en Felipe V, y muy fielmente también en su fiscal, la inquina más sorda y apasionada. Macanaz, pese a la oposición y trabas aragonesas, llevó a cabo su obra "Regalías de los señores reyes de Aragón" ", que le abrió la confianza y predicamento real, y para llevarla a cabo realizó una labor de rastreo por los Archivos del reino, reales o eclesiásticos, y más concretamente por los aragoneses, a la vista de la abundantísima muestra de ejemplares forales, impropios de una biblioteca particular ${ }^{6}$. Este interés por el conocimiento de los viejos privilegios bien pudo Macanaz seguirlo junto a Santiago Riol, nombrado por Macanaz Oficial Mayor de la Secretaría de Cuentas, cargo con el que no dejó de ocuparse de la búsqueda en los Archivos de documentos que sirvieran para documentar o buscar las bases y la extensión de las regalías mayestáticas y que R. Olaechea cita como una constante del regalismo hispánico, a la que denomina como "tendencia exumadora" ?.

La muestra que contiene la librería de documentos forales del territorio aragonés es completísima, apareciendo en menor número los que se ocupan de Valencia, Cataluña o incluso ciudades de estos territorios, que pueden parecer en principio poco relacionadas con los fueros originales, pero cuyos privilegios tenían antiguas relaciones o implicaciones en la evolución foral aragonesa. Además de este material foral primario, otros documentos de apoyatura la completan, como son las alegaciones aragonesas y valencianas civiles y eclesiásticas, así como documentos de mayorazgos territoriales, sin contar con la extensa muestra de autores nacionales dedicados a las leyes de mayorazgos.

El conocimiento de los fueros de la mayor parte del territorio aragonés es evidente que serviría a Macanaz para no dejar ningún cabo suelto en la erradicación de sus

4 GARCIA GOMEZ, M Dolores: "Labiblioteca de Melchor de Macanaz. Fuentes regalistas. Actas Coloquio Carlos III". Inédito.

5 MACANAZ, Melchor: "Regalías de los Señores Reyes de Aragón". Biblioteca jurídica de Autores Españoles. Madrid, 1879.

6 MARTIN GAITE, C.: "Macanaz, otro paciente de la Inquisición'”. Editorial Taurus. Madrid, 1973, p. 44, "El estudio del derecho patrio había que acometerlo al margen de la Universidad... así lo hizo Macanaz, que pasada la Guerra de Sucesión gastaría muchas horas en el Archivo de Simancas, exhumando leyes en que apoyar su parecer".

7 OLAECHEA, R.: "Las relaciones hispano-romanas de la segunda mitad del siglo XVIII. Zaragoza, 1969, pp. 179-180. 
privilegios: damos la relación de los fueros y actos de Corte de Aragón que aparecen en la librería, y la mayor parte de los identificados de ciudades de menor rango. Algunos de ellos tendrían especial interés: "La vigia antigua de Sobrarbe", o la "Historia de San Juan de la Peña" ${ }^{8}$, y sirven de ejemplo al constituir la base histórica jurídica pactista, o planteamiento del recorte del poder real, por la superioridad del reino al rey, siendo estas obras de cronistas y juristas navarro-aragoneses del s. XIII las que, a modo de leyenda, fundamentan este privilegio foral. Sirve de ejemplo, igualmente, el interés por los ordenamientos y fueros de ciudades como Belchite, Calatayud o Daroca, en cuyo origen como municipios de conquista habían recibido privilegios nobiliarios, entregados a los "infanzones" montañeses que se habían ocupado de su defensa, y cuyas exigencias eran mayores". Por último, las muestras de Ordenamientos de Ordenes Militares completan y justifican la actuación de estas órdenes -Templarios, Santiago-, que también por conquista habían recibido distintos privilegios ${ }^{10}$.

La muestra de autores dedicados a fueros, historia o jurisprudencia aragonesa, igualmente podemos decir que es casi completa. Lo es también, casi igualmente la valenciana, siendo más escasa la catalana, sobre todo en sus raíces, no apareciendo por ejemplo, el primer compilador del derecho catalán, Jaume Collis, o Sant Dionis, o Francisco Basset, aunque está justificado por ser la actividad legislativa de los monarcas castellanos menor con respecto a Cataluña y las propias Cortes Catalanas, que aunque tuvieron gran actividad al principio de la Edad Moderna, son inexistentes en el s. XVII y se reúnen sólo dos veces en el s. XVIII " ${ }^{1}$. Pero sí están presentes los autores de literatura jurídica aragonesa, valenciana y catalana que, como veremos, mantenían en la determinación de las sentencias los principios de apoyo foral que sin embargo no es la finalidad aparente de este tipo de informes.

Estas recopilaciones jurídicas podían tener un valor intrínseco para un jurista como Macanaz, y las propias resoluciones jurídicas eran material muy abundante en las regiones citadas, pues en Aragón todos los jueces tenían que indicar al entregar el voto de las sentencias los motivos del mismo, que se registraban en libro consignado para este efecto y que si estaban fundados en la mayoría, formaban una fundamentación jurídica que llegaba a tener carácter incluso oficial: en Castilla, la deliberación jurídica era secreta bajo pena y por tanto no apareció esta abundante literatura jurídica, pues los tribunales castellan no estaban obligados a fundamentar sus decisiones. El interés de Macanaz por las resoluciones concretas y autónomas de las Audiencias se fundamenta en el conocimiento de estas decisiones, que si bien se extraían de casos concretos tomaban carácter oficial por su propia resolución.

A este interés en estas recopilaciones, o "Decissiones", se suma el de rastrear en estas colecciones antiguas resoluciones extraídas de material archivado, pues los auto-

8 MARTINEZ BRIZ, Juan: "Historia de la fundación y antigüedades de San Juan de la Peña". As. 382. - Vigia Antigua de Sobrarbe. As. 141.

9 LALINDE ABADIA, J.: "Los fueros de Aragón". Librería General. Zaragoza, 1979, p. 78.

10 No podemos olvidar que los Maestres de las Ordenes Militares estaban dentro de uno de los cuatro brazos ejecutivos de las Cortes Aragonesas, junto con los caballeros o hijosdalgo.

11 PEREZ MARTIN-SCHOLZ, J. M.: "Legislación y Jurisprudencia en la España del Antiguo Régimen". Universidad de Valencia, 1978. p. 211. 
res consultaban las actas y libros de archivos de los tribunales para documentarse en su trabajo según el tipo de procesos.

Nos informa P. Martín del ejemplo de Fontanella, quien en sus "Decissiones" 12 se refiere repetidamente a "...ut in Archivo vidi...", y a sus comentarios a la luz del derecho catalán de las cláusulas de los contratos matrimoniales, basándose en Actas existentes en el Archivo ${ }^{13}$, y como este decisionista, desde el punto de vista de método de trabajo, muchos de ellos compusieron sus colecciones jurisprudenciales con la ayuda de los documentos procesales archivados: ejemplos concretos los encontramos en Fontanella, que hemos citado, Bas y Galcerán, Miguel de Molino, Calderó, Ramón, León, Sesse y Piñol, etc. Refuerza el interés del conocimiento de estas sentencias el valor que como fuerza de ley tenían las mismas en las Audiencias catalana y valenciana: León justifica esta fuerza "porque el senado valenciano tenía el poder judicial derivado del rey, a cuyas decisiones se les debe dar el mismo valor que a las disposiciones legales" 14 .

Y finalmente podemos resumir el interés que podían tener estas colecciones para Macanaz, vislumbrando en ellas una teoría autónoma y foral, en el hecho intrínseco de la desaparición de las mismas, tras su derogación a partir de la implantación de los Decretos de Nueva Planta, que obligaban a Aragón, Cataluña y Valencia a regularse por el derecho castellano, interrumpiendo de este modo el particular desarrollo jurídico de esos territorios.

De algún autor nos sorprende que no esté incluida su obra más representativa: es el caso de Ferrer, frente a cuyas "Observantiarum Sacrii Regii Cathaloniae Senatus..." - 1580-, aparece en el inventario el "Comentario analítico a la Constitución ac nostra Lerida", cuyas relaciones con antiguos privilegios leridanos podían interesar a Macanaz en los orígenes de los fueros de la ciudad de Valencia, constituidos en gran parte según la costumbre al estilo de Lérida ${ }^{15}$. Nos sirven también en este sentido de posible intencionalidad en el aspecto foral obras jurídicas que aunque, desde luego, forman parte de cualquier biblioteca jurídica del momento, incluimos dentro del apartado foral por sus vinculaciones ciertas, si no evidentes, con el tema. Es buen ejemplo la obra de Pedro Belluga el "Speculum Principis" y que, desde luego, no es una obra de tipo moralizante encaminada a instruiral príncipe antes de subir al trono, o a recordar al propio rey sus deberes de gobernante, como podría concluirse de su título e intención aparente: se dirige al rey recordándole el ejercicio de las funciones conforme a la Justicia, y no oculta que al precisar el alcance de las leyes, quizás resulte algo disminuido el poder real, pero pensando además, no en el carácter nacional de este poder, sino concretándose al reino de Valencia, "en lo que al rey de Valencia puede hacer, en lo que disponen las leyes valencianas. Es un tratado de Derecho público valenciano... tratando todas las cuestiones jurídicas conforme a los fueros y privilegios del reino de Valencia" "17.

12 FONTANELLA, Juan Pedro: "Decisiones Sacri Regii Senatus Cathaloniae", 1639. As. 144.

13 MARTIN-SCHOLZ, P.: "Legislación..." op. cit. pp. 294, 305, 315.

14 MARTIN SCHOLZ, P.: "Legislación..." op. cit. p. 297.

15 LALINDE ABADIA, J.: "Los fueros..." op. cit. p. 75.

16 BELLUGA, Pedro: "Speculum Principis". 1530. As. 84.

17 GARCIA GALLO, A.: "El derecho en el Speculum Principis de Belluga'. A.H.D.E., Madrid, 1963, t. XXIII, pp. 206-208. 
Frente a estos casos, también están los autores aragoneses, Monter de la Cueva, o Vargas Machuca, decisionistas ambos, seguidos menos radicalmente por Cassanate, o Sesse, que enfocan la resolución jurídica de estas "Decissiones", bajo la presión de la romanización del sistema jurídico aragonés de forma abierta y exagerada, olvidando las raíces de las fuentes históricas aragonesas que quedan minimizadas bajo la erudición de derecho romano. El interés por el conocimiento de todos los que se ocupan del tema aragonés abarca a estos casos de posturas menos radicalizadas.

Sólo queda hacer mención de los autores dedicados a las recopilaciones de fueros -de los que sólo se ocupan autores aragoneses-con Miguel de Molino a la cabeza, y su glosador, con cuya obra alcanzó tanta fama como Molino, Gerónimo Portoles, Juan Ibando Bardaxi, o Gil Custodio de Lissa y a los historiadores de la Historia de Aragón, Leonardo, Zurita, Lanuza, Dormer, Sayas y Montemayor. La noticia bibliográfica la exponemos a continuación extraída de la totalidad del trabajo sobre la biblioteca ${ }^{18}$.

\section{FUEROS Y PRIVILEGIOS}

(Autores dedicados a los fueros e historia de Aragón).

- Privilegia Regni Valentie - n⿳⺈ 113.

- Fori Regni Valentie - no 399.

- Fueros de la Diputación de Valencia - nº 232.

- Privilegios de las bolsas de jurados de la Ciudad de Valencia - no 204.

- Vandos y Pragmaticas de Valencia - nº 353.

- Definiciones del Orden de Calatayud - no 287.

- Vigia Antigua de Sobrarbe - n⿳o 137.

- Ordenaciones Reales de Calatayud - $\mathrm{n}^{\mathrm{Q}} 239$.

- Sumario de los Pleitos sobre los estados de Itziar y Belchite - no 264.

- Ordenaciones de la Cruz de Borja - nº 378.

- Actos de Corte de Aragón - no 150.

- Actos de Corte de Zaragoza de 554 - n⿳ 257.

- Actos de Corte del Reino de Aragón - no 339.

- Actos de Corte del Reino de Aragón, en Latín - n 156.

- Actos de Corte del Reino de Aragón - n 370.

- Fueros de Aragón por Carlos II - n 163.

- Fueros de Aragón - Zaragoza - no 151.

- Fueros de Aragón - Zaragoza - n² 152.

- Fueros de Aragón antiguos - Zaragoza - no 274.

- Leyes de Aragón, sin principio ni fin - nº 398.

- Estatutos de Zaragoza - no 246.

- Ordenanzas de la ciudad de Zaragoza - nº 157.

- Estatutos de la Universidad de Zaragoza - n⿳⺈ 158.

- Estatutos de la Universidad de Zaragoza - nº 162.

- Recopilación de la Universidad de Zaragoza del año 35 - n² 159.

18 ALONSO Y LAMBAN, M.: "Apuntes sobre juristas aragoneses de los siglos XVI y XVII. A.H.D.E., Madrid, 1963, t. XXIII, pp. 625-637. 
- Constitución del Colegio de Santiago de la Ciudad de Huesca - n² 155.

- Recopilación de Ordenaciones a Zaragoza de Felipe IV - no 259.

- Recopilaciones de Ordenaciones a Zaragoza de 1628 - nº 262.

- Derechos y Entradas de Mercaderías y Ganados de Aragón - $\mathbf{n}^{2} 156$.

- Sumario de los frutos y rentas de Aragón - nº 369.

- Leyes de Aragón - no 398.

- Baylia General de Aragón - no 448.

- 33 cuadernos de Fueros de Aragón - n 381.

- Leyes y Pragmáticas de Cerdeña - no 324.

- Respuesta de los Vicarios y clero de las Iglesias de Sta. María de Alicante sobre prebeminencias - $\mathrm{n}^{\mathrm{O}} 260$.

- Fueros de Vizcaya - en Medina del Campo - nº 377.

- Ordenaciones de la Comunidad de Daroca - nº 228.

\section{ALEGACIONES Y MAYORAZGOS}

- Diego Morlanes, J.: Alegaciones en favor del reino de Aragón. núms. 159188.

- Luis Martínez: Alegaciones en favor del reino de Aragón. núms. 166-295.

- Alegaciones eclesiásticas de Valencia - n⿳0 354.

- Alegaciones civiles de Valencia - $\mathrm{n}^{\circ} 355$.

- Alegaciones varias (sin especificar lugar o tema): núms. 345-364-350-351356-358-359-360-361-363-364-365.

- Mayorazgos de la Casa de Urrea - núms. 344-346.

\section{RECOPILADORES DE FUEROS ARAGONESES}

- Miguel de Molino - Repertorium... - nำ 294.

Jerónimo Portoles - De consortibus - $\mathrm{n}^{2} 472$.

- Juan Ibando Bardaxi - Suma de los Fueros... - núms. 136-153.

- Luis de Ejea y Talayero - no 375.

\section{HISTORIADORES DE LA CORONA DE ARAGÓN}

- Jerónimo Zurita y Castro - Anales de Aragón - núms. 141-146-443.

- Bartolomé Juan - Leonardo de Argensola - Anales - nº 145.

- Juan de Lanuza - Historia de Aragón - nº 154.

- Francisco Diego Sayas Rabaneda - Anales de Aragón - nº 155.

- Diego José Dormer - Anales-Discursos - núms. 148-149-435.

- Ripia - Corona Real del Pirineo - núms. 178-304-392.

- Juan Francisco Montemayor - Ricos Nombres de Aragón - no 490.

- Juan Martínez Briz - Historia de la Fundación y antigüedades de San Juan de la Peña - $\mathrm{n}^{\mathrm{O}} 382$.

- Jerónimo de Blancas - Coronación de los Reyes de Aragón - nª̣ 426.

- Muerte y Coronación de los Reyes de Aragón - núms. 410-479. 


\section{AUTORES DE COLECCIONES JURIDICAS ARAGONESAS}

- Luis de Casanate - Consiliorum... - nª 374.

- Martín Monter de la Cueva - Decissiones - n² 174.

- José de Sesse y Piñol - Decissiones - no 311

- Juan Crisóstomo de Vargas Machuca - Consideraciones - nº 170.

- Juan Cristóbal de Suelves - Consejos - nº 376.

- Cristóbal Crespi de Valldaura - Observationes... - núms. 17-243.

\section{AUTORES DE COLECCIONES JURIDICAS VALENCIANAS}

- Bas y Galcerán - Theatrum jurisprudentiae - $n^{2} 70$.

- Francisco Jerónimo de León - Decisiones de la Audiencia de Valencia nº 99.

- Pedro Agustín Morla - Emporium Iuris - n² 251.

- Juan Bautista Trobat - De efectibus - $\mathrm{n}^{\circ} 196$.

- Pedro Agustín Morla - Emporium iuris... - no 249.

- Pedro Díaz Noguerol - Allegationes... - n⿳2023.

- Lorenzo Mateu y Sanz - Decissiones - nº 20.

\section{AUTORES DE COLECCIONES JURIDICAS CATALANAS}

- Jaime Cancer - Variae Resolutiones - n⿳ 169.

- Juan Pedro Fontanella - Decissiones - n⿳⺈ 144.

- Juan Pedro Fontanella - Tractatus de Pactis nuptialibus - $\mathrm{n}^{\mathrm{0}} 177$.

- Cortiada - Decissiones - n⿳⺈ 106.

- Caldero - Decissiones - núms. 88-89.

- Antonio Acacio Ripoll - Variae resolutiones - núms. 62-258-492.

- Luis de Pequera - Decissiones - núms. 83-242-272.

- Miguel Ferrer - Comentario analítico... - no 244.

- José Ramón - Consejos...: Decisiones - n 305.

- Francisco Romaguera - Comentaria Constitutiones Synodales - no 267.

- Francisco Molino - Tractatus... de ritu nuptiarium - $n^{2} 270$.

DESCRIPCION BIBLIOGRAFICA DE OBRAS ORIGINALES Y AUTORES OCUPADOS DEL TEMA FORAL DE LA BIBLIOTECA DE MELCHOR DE MACANAZ

\section{Asiento}

17 Dos tomos de Crepi Observationes. Lugduni ......................... 050

20 Un tomo Matheo de re criminali. Lugduni ............................ 055

23 Un tomo de Noguerol: Allegationes Iuris. In Lugduni ............ 030 
CRISTOBAL CRESPI DE VALLDAURA Y PARIZUELA (1599-1671). Como su título anuncia, es esta obra el resumen de una especie de diario escrito a lo largo del ejercicio de veinte años como Presidente y vicecanciller del Consejo Supremo de la Corona de Aragón: las mismas "sencillísimas costumbres" que según N. Antonio atrajeron la atención de Felipe IV a este ilustre personaje, son distintivo de la exposición de estas "Observationes..." que por otra parte sirven de retrato fiel al espíritu jurídico que se vivía en los tribunales.

OBSERVATIONES ILLUSTRAE DECISSIONIBUS SACRI SUPREMI REGI ARAGONUM CONSILII, SUPREMI CONSILII S. CRUCIATAE ET REGIAE AUDENTIAE VALENTINAE. Lugduni Horace Boissart, 1662. Texto latín-catalán-castellano. 2 vols., fol. 23 h., 528 p. $=2$ h., 414 p., 58 h. Lugduni Horace Boissart, 1667. 2 vols. Gran fol. 23 h., 528 p. $=2$ h., 414 p., 58 h. Ref.: N. ANTONIO, t. I, p. 243; PALAU, t. IV, p. 176, no 64353; ESPASA, t. XVI, p. 131; B. Valentina, JOSEPH RODRIGUEZ, t. I, p. 95; B. Valentina, XIMENO, t. II, p. 27; PEREZ MARTIN, A., p. 320 (Colegio de Abogados de Barcelona, Catálogo).

20

LORENZO MATEU Y SANZ. Este autor valenciano, además de sus obras de recopilación de fueros valencianos, es autor de estas "decisiones" en las que demuestra una gran erudición clásica, histórica, y también jurídica, tanto de su país como de la catalana, castellana y aragonesa. Como juez de causas civiles fue individuo del Consejo de Indias y del Consejo Supremo de Aragón.

TRACTATUS DE RE CRIMINALI SIVE CONTROVERSIARUM USU FREQUENTIUM IN CAUSIS CRIMINALIBUS CUM EARUM DECISSIONIBUS TAM IN AULA HISPANA SUPREMA CRIMINUM.

Lugduni, Cludium Bourgeat, 1676, fol.

Además de esta edición que Palau da como 1ํㅗㄹ están: Lugduni, 1677.

Lugduni, 1696, fol.

Lugduni, 1686, C. Bourgeat, fol.

Lugduni, 1702, Anisson, fol.

Lugduni, 1704, fol. 15 h. 618 p. 33 h.

Ref.: PALAU, t. VIII, p. 361, $\mathrm{n}^{\mathrm{o}}$ 158154; ESPASA, t. 33, p. 966; N. ANTONIO, t. II, p. 5; PEREZ-MARTIN, A., p. 321; GISBERT, p. 406; VALENTINA XIMENO, t. I, p. 271.

23

PEDRO DIEZ NOGUEROL. Allegationes Iuris. Lugduni, 1631 - 1641

Ref: N. ANTONIO, t. II, p. 189; PEREZ-MARTIN, p. 320.

Asiento

62 Ripoll: varias resoluciones; in Lugduni .................................. 024

70 Bas: Teatro Iurisprudentie: en Valencia .................................. 010

83 Decisiones de Peque $1^{\underline{a}}$ et $2^{\underline{a}}$ parte en Barcelona ...................... 028

84 Belluga Speculum Principum en Bruxelas ............................... 050 
ACACIO ANTONIO DE RIPOLL. De este jurista catalán formado en Salamanca, aunque ejerció como catedrático en Huesca y fue Juez General de Cataluña durante 16 años, hay en la lib. varias obras. Esta VARIAE JURIS RESOLUTIONES MULTIS DIVERSORUM SENATUM DECISIONIBUS ILLUSTRATAE. Lugduni, 1531, fol. Vid. núms. 258-492.

- Variae juris resolutiones. Lugduni, Sumptibus Jacobi Andrea, 1630, fol. 4 h., $528 \mathrm{p}$.

- Lugduni, 1631.

Ref.: PALAU, t. XVII, p. 56, nº 269180; ESPASA, t. 51, p. 784; N. ANTONIO, t. I, p. 2; PEREZ MARTIN, p. 318.

NICOLAS BAS Y GALCERAN. Contiene esta $1^{\underline{a}}$ edición de este autor valenciano un gran número de modelos de documentos jurídicos utilizados en la jurisprudencia catalana.

THEATRUM JURISPRUDENTIAE FORENSIS VALENTINAE ROMANORUM JURI MIRIFICE ACCOMMODATAE. Valentiae Typ. Laurentii Mesnier coram Diputationis Domo, 1690, 2 vol. fol.

Ref.: PALAU, t. II, p. 103, no 25218; B. Valentina Joseph, R, t. I, p. 353; PEREZ MARTIN, p. 322: B.N. 7/58938-39.

\section{3}

Se trata de LLUIS DE PEQUERA, que es junto con Jaime Cancer, el mejor jurista catalán del s. XVI, por la aportación que supuso su obra en la que recogía el derecho consuetudinario de prácticas forenses. Reflejo además de su interés y conocimiento de la jurisprudencia catalana son las DECISSIONES CATALONIAE SENATUS. Barcinonae, 1605.

Barcinonae. Huberti Gotart, 1585. Barcinonae, 1611.

Ref.: PALAU, t. XII, p. 415, no 216337; N. ANTONIO, t. II, p. 59; C.B.O. XXVIII-4-2; P. MARTIN, p. 318.

\section{4}

PEDRO DE BELLUGA. Es esta la tercera edición y única de Bruselas, con adiciones y comentarios de Camillo Borrello de la obra de este jurista valenciano. La relación inventarial indica sólo un volumen aunque la división primera del autor establecía 48 rúbricas, agrupadas en tres partes, y García Gallo habla de la Conclusión en Almansa del libro 17, el año 1441.

SPECULUM PRINCIPUM IN QUO UNIVERSA IMPERATORUM, REGUM, PRINCIPUM... Cum addiotinibus et comentariis D. Camilli Borelli. Bruxelae, Francisco Vivien, 1655, fol. 11 h. 590 p. 14 h. (B.U.Barcelona; B.P. Navarra; B.U. Salamanca; B.U. Santiago).

Ref.: PALAU, t. II, p. 152, núms. 27026-27027; ESPASA, t. VIII, p. 1609;

XIMENO VALENTINO, t. I, p. 27; SALVAT, t. IV, p. 366; GARCIA GALLO, p. 191. 
88 Ramírez de Lege regia en Alemania .......................................... 015

893 Caldero; Decisiones; en Alemania ............................................ 015

106 Cortiada. Decisiones y Contenciones Gerunde ............................ 150

113 Privilegia Regni Valentia antiguo ……….................................. 130

PEDRO CALIXTO RAMIREZ (1556-1627). Nos hace desconocer la imprecisión tipográfica la posible edición de esta obra de este jurista aragonés, Juez extraordinario de la Real Chancillería y de la Corte de Justicia, así como catedrático de Zaragoza. Informa Alonso y Lamban de sus posibles estudios de Derecho privado foral, manuscritos, que justifica el interés de Macanaz por este autor, con esta obra, no dedicada a estos temas. No hay entre las obtenidas ninguna edición alemana, de la que sólo conocemos una edición en Zaragoza:

ANALYTICUS TRACTATUS DE LEGE REGIA QUA IN PRINCIPIS SUPREMA ET ABSOLUTA POTESTAS TRANSLATA FUIT, CUM QUODAM CORPORIS POLITICI AD INSTAR PHISICI ACPTIS ET MEMBRORUM CONEXIONE. Ad Philippum III. Caesaraugusta, 1616, fol. 14 h. 423 p. 8 h. (B. Colg. Abogados Madrid).

Ref.: PALAU, t. XV, p. 55, nº 246810; N. ANTONIO t. II, p. 177; ESPASA, t. 49, p. 521; ALONSO Y LAMBAN, M., p. 637.

Las vicisitudes de la vida de MIGUEL CALDERO podían haber interesado tanto a Macanaz como las conclusiones como jurista de su obra: siendo miembro del Consejo Real este eclesiástico se opuso violentamente a la Inquisición por lo que fue excomulgado, aunque el Consejo de Aragón castigó por ello a los inquisidores y restableció su posición.

SACRI REGII CRIMINALIS CONCILI CATHALONIAE DECISIONES. I-IVI-III. Barcinonae Typ. Antonii Ferrer, 1686-1701 - 3 partes, fol. No cita Palau ninguna edición alemana.

Ref.: DIC. CATALAN, t. IV, p. 135; PALAU, t. III, p. 41, n² 39683; PEREZ MARTIN, p. 321.

106

MIGUEL CORTEADA: Estas "DECISIONES REVERENDI CANCELARII ET SACRI REGII SENATUS CATHALONIAE"' I-IV, Barcinonae, 1661-1665; 16861689 de este jurista, Regente de la Audiencia de Cataluña y Catedrático de Derecho Romano en Lérida; ha sido obra a veces confundida con la de su padre homónimo. p. 103.

Ref.: DIC. CATALAN, t. 5, p. 656; PEREZ MARTIN, p. 320; SIMON, t. IX,

PRIVILEGIA REGNI VALENTIAE.

Bajo este enunciado ninguna referencia designa una obra: puede tratarse del 
"Aureum opus regalium privilegiorum civitatis et regni Valentiae" de Luis de Alanya, Valencia 1515, y que contiene privilegios reales desde 1236 a 1515.

Ref.: PEREZ MARTIN, p. 266.

\section{Asiento}

136 Comentar Bardaxi Superforos Aragoniae Caesaraugustae ........... 020

144 Fontanella, Decisiones en Barcelona .......................................... 090

145 Anales de Leonardo en Aragón ............................................... 022

146 Zurita Anales de Aragón con el Indice en Zaragoza .................... 200

147 Indice de Zorita en Latín. En Zaragoza ........................................ 010

148 Dormer. Anales de Aragon, en Zaragoza ................................. 022

149 Progresos de la Historia en Zaragoza ....................................... 020

136

IBANDO BARDAXI. Este jurisconsulto, gobernador general de Aragón, es el primero que encontramos de la larga lista de autores aragoneses dedicados al tema foral.

SUMMA DE FUEROS Y OBSERVANCIAS DEL REYNO DE ARAGON: Y DE LAS DETERMINACIONES Y PRACTICAS REFERIDAS POR MICER MIGUEL DEL MOLINO EN SU REPERTORIO. Caragoca. En casa de Juan de Altaraque, 1587 (B.N.) o bien, COMENTARII IN QUATTUOR ARAGONENSIUM FORORUM LIBROS. Caesaraugustae Laurentino Robles, 1592 (B.N. Madrid; B.U. Salamanca; B.P. Tarragona; B.P. Teruel; B.U. Zaragoza).

Ref.: PALAU, t. II, p. 71, n² 22781; N. ANTONIO, t. I, p. 622. ALONSO Y LAMBAN, p. 631 .

\section{4}

JUAN PEDRO FONTANELLA (1576-1680). DECISIONES SACRI REGII SENATUS CATHALONIAE. I-II Barcinonae, 1639-1645. Sumpt. Perachon et Cramer.

Ref.: PALAU, t. V, p. 457, n 93374; ESPASA, t. 24, p. 335; PEREZ MARTIN, p. 318; C.B.O., 99-1-3/4.

BARTOLOME JUAN LEONARDO DE ARGENSOLA (1562-1631). PRIMERA PARTE DE LOS ANALES DE ARAGON QUE PROSIGUE LOS DEL SECRETARIO GERONIMO CURITA DESDE EL AÑO MDXVI. Caragoca. Juan de Lanaja, 1630, fol. portada grab. en cobre por Jose Valles. 14 h. 1128 p.

Ref.: ESPASA, t. 30, p. 7; PALAU, t. I, p. 462, n² 16096.

JERONIMO ZURITA Y CASTRO (1512-1580). Encargado por Carlos V y 
luego por Felipe II de recoger todos los papeles del Reino para formar el Archivo de Simancas, tuvo material y 30 años de tiempo para la redacción de los "Anales".

ANALES DE LA CORONA DE ARAGON. Caragoca, Pedro Bermuz \& Domingo Portonaris, 1562-1579. $2^{2}$ parte 4 vols. fol. de cinco libros de cada uno. La inclusión del INDICE DE LAS COSAS MAS NOTABLES QUE SE HALLAN EN LAS QUATRO PARTES DE LOS ANALES Y LOS DOS DE LA HISTORIA, es en las ediciones de 1604-1621 y 1671.

Ref:: PALAU, t. XVIII, p. 473, núms. 381752 y 381762 ; N. ANTONIO, t. I, p. 604; ESPASA, t. 70, p. 1566.

\section{8}

DIEGO JOSE DORMER. ANALES DE ARAGON DESDE EL AÑO MDXXV DEL NACIMIENTO DE NUESTRO REDEMPTOR HASTA EL DE MD L. AÑADENSE PRIMERO ALGUNAS NOTICIAS MUY IMPORTANTES DESDE EL AÑO MDXVI HASTA EL DE MDXXV. Zaragoza, herederos de Diego Dormer, 1697. fol. front. grab. en cobre por Juan Renedy, 36 h. 700 p. 22 h.

Ref.: PALAU, t. IV, p. 517, $\mathbf{n}^{\mathrm{g}}$ 75750; ESPASA, t. 18, p. 2032.

149

DIEGO JOSE DORMER: La B. Valentina de Joseph Rodríguez es la única que atribuye a Dormer "Los Progresos de la Historia".

Asiento

150 Actos de Corte del Reino de Aragón en Zaragoza ................. 020

\section{0}

Por lo abundantemente que el tema foral está representado en la Biblioteca, damos de las ediciones de ACTOS DE CORTE Y FUEROS conjuntamente ante la parquedad de la información en asientos concretos. Toda la información está recogida del estudio de P. Martín, en su obra "Fori...". En algunos casos se recogen juntos FUEROS Y ACTOS DE CORTES -costumbre que se impondría desde 1592aunque distinguiendo cuando es Fuero y cuando es Acta -hasta 1686, que ya no se hace la distinción-. as. núms. 150-156-257-339-370.

Como los fueros, no todos han sido recogidos en las ediciones impresas, y nos consta la existencia de Actos de Corte que no están recogidos en ninguna de las recopilaciones existentes (p.e.: los Actos de Cortes de 1678, presididos por el Duque de Hijar).

En las Cortes de Teruel de 1427-28, se encargó a Martín Díaz de Aux para que con una comisión de seis letrados recogiera en libro, los usos, observancias y actos de Corte del reino; sólo juzgaron conveniente recoger dieciséis actos de Corte. De ellos, los celebrados en las Cortes de Zaragoza son: 2 en 1364; 1 en 1367; 4 en 1380; 5 en 1398 ; y 3 en 1413.

Se llevó a cabo también una recopilación de los Actos de Corte de que se tuviera memoria, hecha por una comisión tras las Cortes de Aragón de 1552, que publicó en 1554 los resultados de su labor: recogió 64 Actos de Corte, y de ellos en las Cortes de 
Zaragoza son: 2 en 1376; 2 en 1398; 2 en 1414; 2 en 1413-14; 2 en 1446; 2 en 1451, y 2 en 1518-19.

Se han conservado además 109 Actos de Cortes y de ellos, resueltos en las Cortes de Zaragoza, son: 13 en 1646 y 44 en 1678.

De estos Actos de Corte, aparte de los contenidos en las Observaciones de Martín Díaz de Aux, se han hecho las siguientes ediciones en Zaragoza: ACTOS DE CORTE DEL REINO DE ARAGON. Zaragoza, 1554. Fue llevado a cabo por las Cortes de Monzón en 1552 e impreso por Pedro Bermuz (contiene Actos que van desde las Cortes de Cariñena, en 1360, a las de Monzón en 1512) fol. got. 6 h. 90 fols. Vid. $n^{2} 257$.

ACTOS DE CORTE DEL REINO DE ARAGON. Zaragoza, 1584. Añade los Actos de Corte de 1564. Contiene anotaciones de Juan Miguel Pérez de Bodalva.

ACTOS DE CORTE DEL REINO DE ARAGON... Impresión por los Señores Diputados... de los Actos de Corte de 1584. Zaragoza, 1608. Fue impresa por Lorenzo Robles y es una reproducción de la edición de 1584 a la que añade los Actos de Corte de 1585 y 1592.8 h. 92 fols. 5 h.

ACTOS DE CORTE DEL REYNO DE ARAGON. Zaragoza, 1664: es una reimpresión llevada a cabo por los herederos de Pedro Lanaja y Lamarca, de la realizada en 1608, añadiendo el Acto de Corte de 1564. fol. 8 h. 97 fol.

FUEROS, OBSERVANCIAS Y ACTOS DE CORTE DEL REINO DE ARAGON. I-II. Zaragoza, 1866. Esta colección que es la más completa y manejable actualmente de los Actos de Corte, como vemos por el año, está fuera de la fecha de la biblioteca, por lo que el as. reseñado con este título debía corresponder a alguno de los que hemos indicado en los Actos de Corte. Conocemos la ref. de unos Fueros y Actos de Corte del Reino de Aragón hechos en las Cortes de... Taracona de MDXCI en Zaragoza, Lorenzo de Robles 1593, fol. 2 h. 40 p., que no reseña nuestra mejor fundada información, pero que apuntamos. Ref.: FORI ARAGONUM, p. 45; PAL, t. V, p. 524, núms. 95570 y 95563 , y, t. IV, p. 136, nº 63049.

\section{Asiento}

151 Fueros de Aragón, en Zaragoza ........................................... 024

152 Fueros de Aragón, en Zaragoza ........................................... 024

As. núms. 151-152-163-274-381-398.

Como en el caso de los Actos de Corte, damos la relación bibliográfica de todos los as. referidos a este tema, recogida del estudio de los "FORI ARAGONUM". La deficiencia en la actualidad de estos manuscritos -de los que tan bien surtida está la biblioteca- se debe a los exprugos sistemáticos de los fueros por parte de Pedro IV de Aragón y por Felipe II, así como por los incendios de la Guerra de la Independencia. No podemos sin embargo asegurar que estos asientos contengan obras manuscritas, pues la ausencia de esta aclaración por parte del escribano no significa certeza en uno u otro sentido. Damos pues el número de las ediciones impresas: 
- I⿳亠口 edición: Comprende los FUEROS DE ARAGON, sin portada ni colofón, ni indicaciones de fecha y año de impresión. Comprende desde la Compilación de Huesca, hasta las Cortes de Zaragoza de 1467, más las Observancias de Martín Díaz de Aux. Ureña dice que la edición fue en Zaragoza entre Nov. de 1476 y Abril de 1477.

- 2a edición: en Zaragoza, en 1496, por Pablo de Hurus bajo la dirección de Gonzalo de Santa María.

- 3" edición: en Zaragoza, en 1517 por Jorge Coci: se limitó a reproducir la edición de 1496, incluso con la misma paginación: el director técnico fue Miguel de Molino.

- 4a edición: en Zaragoza, por Juana Millian, viuda de Pedro Harduyn, en 1542, bajo la dirección de Micer Gil de Luna. Las ediciones posteriorres de los Fueros, en 1542 reprodujeron íntegramente esta última, conservando la paginación y yuxtaponiendo al final del libro IX los Fueros de Cortes sucesivos, ordenados cronológicamente. Ante la imposibilidad de precisar la edición señalada, sólo damos esta información general.

Los Fueros de Aragón referidos a su parte más significativa se contraponen a los Actos de Corte, aunque la distinción no siempre es clara y en los textos forales se utilizan ambas expresiones indistintamente. La carencia de una recopilación oficial del Derecho aragonés traía como lógica secuela la inseguridad jurídica y sólo los juristas guardaban para sí las pocas copias existentes de derecho aragonés.

A partir de las Cortes de Huesca, de 1247, Jaime I redactó una Compilación oficial en latín -aunque también se hizo en romance para el mejor manejo de los asistentes a la asamblea - y en latín se promulgaron todos los fueros hasta las Cortes de 1398. En las mismas Cortes de 1247, se encargó a Vidal de Canellas que llevara a cabo una compilación definitiva que efectuó en 9 libros, titulados: "In excelsis Dei Thesauris", siguiendo el orden establecido en el Código Justinianeo: los ejemplares de esta obra eran ya escasos a principios del s. XVI. En este punto no podemos sino aventurar, por el especial interés foral y bibliográfico de Macanaz, que pudiera tener una de estas Compilaciones.

En la actualidad nos consta la existencia de 10 manuscritos latinos de los fueros de Aragón, contenidos en las Secciones de Manuscritos de las Bibliotecas Colombinas, Museo Británico, Biblioteca del Escorial, Catedral de Tortosa, Biblioteca Nacional, Monasterio de la Cogolluda (Zaragoza, B.P. y U.) (v. Fori, p. 36).

Ref.: FORI, pp. 13, 16, 36, 40; PALAU, t. V, p. 524; G. GALLO, p. 427.

Asiento

153 Bardagis in foro Aragonum: en Zaragoza .............................. 020

154 Lanuza: Historia de Aragón. Tom. $2^{\circ}$ - Idem …….................. 012

155 Sayas: Anales de Aragón: Idem ........................................... 022

156 Actos de Corte de Aragón, en Latín .......................................... 024

157 Ordenaciones de la ciudad de Zaragoza .................................. 030

158 Estatutos de la Universidad de Zaragoza ................................ 000

153

IBANDO BARDAXI. SUMMA DE LOS FUEROS Y OBSERVANCIAS DEL 
REINO DE ARAGON: Y DE LAS DETERMINACIONES Y PRACTICAS REFERIDAS POR MECER MIGUEL DEL MOLINO EN SU REPERTORIO. Caragoca. En casa de Juan de Altaraque, 1578 (B.N. Madrid); Zaragoza, 1624.

COMENTARII IN QUATTUR ARAGONENSIUM FORORUM LIBROS. Caesaraugusta Laurentino Robles, 1592 (B.N. Madrid; B.U. Salamanca; B.P. Tarragona; B.P. Teruel; B.U. Zaragoza).

Ref.: N. ANTONIO, t. I, p. 622; PALAU, t. II, p. 71; B.R.P., t. I, p. 117; ALONSO Y LAMBAN, p. 629.

154

JUAN DE LANUZA. Si de este autor se tratara -aunque no le conocemos la "Historia" - su heroica resistencia defendiendo los fueros aragoneses contra Felipe II -por lo que fue decapitado- podría tener especial interés para Macanaz, para conocer sus opiniones históricas: también podría ser MARTIN FERRER DE LANUZA, "Cortes y Sucesos de Aragón", o IGNACIO LANUZA.

Ref.: ESPASA, t. 29, p. 702.

155

FRANCISCO DIEGO DE SAYAS RABANEDA Y ORTUBIA (ob. 1680). Cronista de Felipe II en Aragón. ANALES DE ARAGON DESDE EL AÑO 1520 DEL NAC. DEL SEÑOR HASTA NUESTROS DIAS. Zaragoza, 1666.

Ref.: N. ANTONIO, t. I, p. 420; ESPASA, t. 54, p. 820.

157

LIBRO DE LA RECOPILACION DE LAS ORDINACIONES DE LA CESAREA E INCLITA CIUDAD DE CARAGOCA, 1567, fol. got. 8 h. 82 fols. 1 h. (B.U. Zaragoza) y $1595-1608-1646-1652-1659-1669-1693-1705$.

Ref.: PALAU, t. XV, p. 305, núms. 252573 y 252575, p. 455; PEREZ MARTIN, p. 208.

\section{8}

ESTATUTOS DE LA UNIVERSIDAD Y ESTUDIO GENERAL DE LA CIUDAD DE CARAGOCA. HECHOS POR LOS SRES. JURADOS CAPITOL Y CONSEJO DE AQUELLA. Caragoca, Juan de Lanaja y Quartanet, 1618, fol. 5 h. 122 p. 3 h. (B.U. Zaragoza).

Id. Y CONFORMADOS POR LA MAJESTAD CATOLICA DE FELIPE III. Caragoca, Pedro de Lanaja y Lamarca, 1647, fol. 4 h. 96 p. 4 h. (B. San Carlos Zaragoza).

Id. Y CONFIRMADOS POR FELIPE IV, 1659, fol. 4 h. 96 fols. 4 h. (B.U. Zaragoza).

Ref.: PALAU, t. V, p. $168, \mathrm{n}^{\mathrm{o}} 85561$.

Asiento

159 Recopilación de los Estatutos de la Ciudad de Zaragoza en el año 35 010 
160 Constituciones del Colegio de Santiago de la ciudad de Huesca 006

161 Indice de Derechos y Entradas de Mercaderías y Ganados en el Reino de Aragón .................................................................... 001

162 Estatutos de la Universidad de Zaragoza ................................... 006

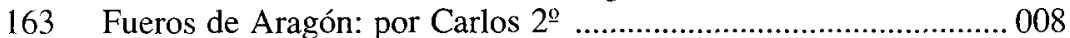

1692 Cancer, Varias Resoluciones, en Lugduni ............................ 030

170 Consideraciones de Vargas, en Nápoles ................................ 024

159

RECOPILACION DE LOS ESTATUTOS DE LA CIUDAD DE ZARAGOZA. POR LOS SEÑORES JURADOS CAPITOL Y CONSEJO CON PODER DEL CONCELLO GENERAL, CONFIRMADOS Y DECRETADOS EL PRIMERO DE DICIEMBRE DE 1635. Zaragoza. Hospital Real y General de Nuestra Señora de Gracia, fol. 2 h. 312 p. 5 h. (B.U. Zaragoza). Sólo tenemos esta referencia del año 35 , desconociendo la del año 33 y del año 28 del n 262 .

Ref.: PALAU, t. XIV, p. 298, nº 252473.

162

Vid. No 158 .

163

FUEROS Y ACTOS DE CORTES DEL REINO DE ARAGON hechos por la Sacra, Católica y Real Majestad del Rey D. Carlos II, Nuestro Señor, en la ciudad de Calatayud. En Zaragoza, por Pascual Bueno, 1678. Gran folio 2 h. 36 fol. IT. 1686, Gran folio, 2 h. 16 fol.

Bajo el reinado de Carlos II se reunieron dos veces las Cortes aragonesas: con el contenido se publicó un cuaderno foral en 1677-78, de las convocadas en Zaragoza el 17 de marzo de 1648 y contenían 73 fueros bajo 73 rúbricas. En las segundas, de 1684-87, de Zaragoza, se promulgaron 20 fueros.

Ref.: PALAU, t. V, p. 525, nº 95577; FORI, p. 32; PEREZ MARTIN, p. 198.

169

JAIME CANCER: VARIARUM RESOLUTIONUM IURIS CAESAREI PONTIFICII ET MUNICIPALIS PRINCIPATUS CATHALONIAE PARS PRIMA. Lugduni, Laurentii Durandum, 1635.

Lugduni, Laurentii Ardano, 1644

Lugduni, 1659 - 1683.

Estas ediciones de N. Antonio difieren de las de Palau -Philippi- Borde, 1658, fols. 1670 y 1683. El éxito de esta obra se justifica por el estudio de los problemas jurídicos y el enfoque convergente del punto de vista del derecho romano, catalán y canónico.

Ref.: N. ANTONIO, t. I, p. 618; PALAU, t. III, p. 96, núms. 41845, 41846 y 41847; C.B.O. XXIX-3-6.

JUAN CRISOSTOMO VARGAS MACHUCA. De la obra de este "pactista" 
aragonés, dice P. Martín que las ediciones napolitanas fueron usadas solamente para la comparación con las aragonesas, que fueron de mayor manejo y más amplia difusión.

CONSIDERACIONES PRACTICAS PARA EL SINDICO DE JUSTICIA DE ARAGON, SUS LUGARTENIENTES Y OTROS OFICIALES. Nápoles, Luis Cauallo, 1688, fol. 2 vols.; I: 2 I h. 49 p. $=$ II: 36 h. 4 p.

Nápoles, Nouello de Bonis, 1671, fol. 2 vols.; I: 21 h. 49 p. = II: 36 h. 4 p. Nápoles. Pero está encabezado con "Decisiones", en lugar de "Consideraciones".

Ref.: PALAU, t. XXV, p. 282, núms. 352479-80-81; PEREZ MARTIN, p. 321: ALONSO Y LAMBAN, p. 627.

Asiento

1733 Fontanella, de Pactis en Barcelona ................................... 024

174 Decisiones de Monter, en Zaragoza .................................... 010

188 Morlanes: Alegaciones en favor del Reyno de Aragón impresso en Zaragoza ......................................................... 022

239 Ordenaciones de Calatayud ............................................... 004

240 Pequera. Iuris Consultis, en Barcelona ............................... 008

241 Silva. Respolsorum Iuris - en Madrid ............................... 010

173

JUAN PEDRO FONTANELLA. Vid. as. nำ 140 y DE PACTIS NUPTIALIBUS SIVE DE CAPITULIS MATRIMONIALIBUS TRACTATUS. Barcinonae, Laurentium Dev. 1612-1622.

Ref.: PALAU, t. V, p. 457, no 93374; ESPASA, t. 24, p. 335; P. MARTIN, p. 318 ; C.B.O., 99-1-3/4.

174

MARTIN MONTER DE LA CUEVA. DECISSIONUM SACRAE REGIAE AUDIENTIA CAUSARUM CIVILIUM REGNI ARAGONUM DISCURSU THEORICO ET PRACTICO COMPACTARUM. Caesaraugustae ex Ageli Tanani MDCI (al fin).

Caesaraugustae Typis Ioannis Perez a Valdivieso anno a Virginis Partis, $1598,4^{\circ}$ marquilla, 28 h. 602 p. 1 h. (B.N. Madrid).

Ref.: PALAU, t. X, p. 110, nº 178314; ESPASA, t. 36, p. 575.

188

DIEGO MORLANES: ALEGACIONES EN FAVOR DEL REINO DE ARAGON EN LA CAUSA DEL VIRREY EXTRANJERO QUE LA MAJESTAD DE NUESTRO SR. TRATA EN LA CORTE DEL ILMO. SR. D. JUAN DE LANUZA Y PERELLOR, JUSTICIA DE ARAGON, VIZCONDE DE RODA. Zaragoza, 1591. Caragoca, en casa de Lorenzo Robles año MDXCI, fol. 24 h. 560 p. 1 h. (B.N. Madrid).

Ref.: PALAU, t. X, p. 269, nº 183124; N. ANTONIO, t. I, p. 300; ESPASA, t. 36, p. 1120 . 
ORDINACIONES REALES DE CALATAYUD. Caragoca, 1625.

ORDINACIONES REALES DE CALATAYUD, Cristóbal de la Torre, 1637, 4", 4 fols. 143 p.

ORDINACIONES DE LA COMUNIDAD DE CALATAYUD, 1671 (B.N. Madrid).

ORDINACIONES DE LA CIUDAD DE CALATAYUD, por D. Luis de Exea y Descartin. Zaragoza, Herederos de Diego Dormer, 1674, fol. 2 h. 146 p. $1 \mathrm{~h}$.

ORDINACIONES REALES DE CALATAYUD, 1683. Calatayud. Cristóbal Gálvez, fol.

ORDINACIONES REALES DE LA COMUNIDAD DE CALATAYUD. Caragoca. Pascual Bueno, 1692, fol. 2 h. 72 p. 1 h.

ORDINACIONES REALES DE LA CIUDAD DE CALATAYUD, 1693, fol. 10 h. 27 p.

Ref.: PALAU, t. XI, p. 453, núms. 203348 a 203354; PEREZ MARTIN, p. 197.

\section{0}

LUIS DE PEQUERA: DE IURE PRAELATIONES ... Barcinonae. Ex. off. Petrum Mali. 1577, fol. 6 h. 129 fols. 13 h. (Vid. núms. 83 y 277).

241

Por la dedicación a los temas de ascendencias, mayorazgos, árboles genealógicos, casas solariegas, etc., que en otras tantas ocasiones interesan a Macanaz hemos pensado, dada la imprecisión de la referencia y del título, en Roderico Méndez de Silva, autor igualmente del "Gran Justicia de Aragón", Madrid, 1653, del que no dice sin embargo sea autor de esta obra con este título.

\section{Asiento}

244 Ferrer. Comenttas; Analiticus en Lérida ..................................... 012

248 Estatuto de Zaragoza................................................................ 006

249 Morla: Emporium Turis; Lugduni ................................................ 012

252 Recopilaciones de Ordenaciones de Zaragoza por Felipe IV ........ 010

270 Molinus de Pactis nuptialibus - Barcelona ........................................ 006

274 Fueros de Aragón antiguos en Zaragoza ..................................... 008

275 Picbardo Super Instituta 2ำ Tomo en Génova ................................ 024

\section{4}

MIGUEL FERRER: COMENTARIO ANALITICO A LA CONSTITUCION AC NOSTRA LERIDA. Luis Menescal, 1618-1619. Con la inclusión de esta obra demuestra Macanaz más interés por la formación de la constitución leridana que por sus conocidísimas y utilizadísimas "Decissiones" jurídicas.

Ref.: PALAU, t. V, p. 363, no 90361; N. ANTONIO, t. II, p. 135; PEREZ MARTIN, t. I, p. 317. 
ESTATUTOS DE LA CIUDAD DE ZARAGOZA. Zaragoza, 1636, fol. Ref.: PALAU, t. V, p. $168, n^{\circ} 85568$.

PEDRO AGUSTIN MORLA. Se formó este valenciano en Salamanca junto con Espino y Salcedo. Ni Palau ni N. Antonio citan la edición de Lyon, y en la edición de Valencia dice Palau dar Morla en el Prólogo el primer Catálogo impreso de escritores valencianos. EMPORIUM UTRIUSQUE IURIS QUAESTRIONUM IN USU FORENSI AD MODUM FREQUENTIUM. Lugduni, 1599.

Ref.: PALAU, t. X, p. 268, $\mathbf{n}^{\mathrm{9}} 183103$; N. ANTONIO, t. II, p. 172; ESPASA, t. 36, p. 1117; C.B.O. 98-3-14; GISBERT, p. 404; C.B.R., p. 261.

\section{2}

RECOPILACIONES DE TODAS LAS ORDENACIONES CONCEDIDAS por el Rey Don Felipe, Nuestro Señor, a la Ciudad de Caragoca. Juan de Lanaja y Quartanet Impressor del Reyno de Aragón y de la Universidad $16284^{\circ}(29 \mathrm{~cm}) 8$ fols. 145 p. 1 lám. con un escudo grabado.

Ref.: PALAU, t. XV, p. 305, n 252575; PEREZ MARTIN, p. 208.

270

FRANCISCO MOLINO: TRACTATUS CELEBRIS ET INSIGNIS DE RITU NUPTIARUM, ET PACTIS IN MATRIMONIO CONUENTIS. Barcinonae. Laurentii Deu expensis Ioannis Simon 1617, fol. 12 h. 370 fols.; Item. 1618 (Arch. Hist. Barcelona; B.N. Madrid).

Ref.: PALAU, t. IX, p. 498, $\mathrm{n}^{\mathrm{Q}} 175057$.

\section{4}

FUEROS DE ARAGON ANTIGUOS EN ZARAGOZA. Vid. $\mathrm{n}^{\circ} 151$.

La $1^{\text {a }}$ recopilación de que hemos hablado en 1476 ó 1477, titulada "Fueros y Observancias del Reino de Aragón", ha tenido el sobrenombre de "viejo", según informa G. Gallo: no sabemos si en la época del inventario ya sería considerada como tal, y en caso de serlo si podríamos equiparar el adjetivo de viejo al de antiguo, como aquí indica, para poder identificar esta edición.

\section{5}

Vid. $\mathrm{n}^{\mathrm{0}}$ 60. Aquí se trata de la edición genovesa de ANTONIO PICHARDUS, autor de la conocida obra -según N. Antonio de tan altos valores filosóficos y morales fundamentados dialécticamente- "Practicae Institutiones sive Manudictionum iuris civilis Romanorum Regi Hispania ad Praxium". Genevae, 1657, fol., Samuelis Chouet.

Ref.: PALAU, t. XIII, p. 215, no 225390; N. ANTONIO, t. I, p. 153; ESPASA, t. 44, p. 595; B.R.P., t. I, p. 118. 
293 Alegaciones de Martínez del Reino de Aragón, en Zaragoza ..... 006

294 Repertorio de Molino en Zaragoza....................................... 010

304 Ripia, Corona del Pirineo, en Zaragoza ...................................... 010

305 Consejos de Pamonio, en Barcelona .......................................... 010

310 Decisiones de Sesse: Tomos $3^{\circ}$ y $4^{\circ}$, en Zaragoza ..................... 024

311 De Sesse. De inivitionibus en Barzelona ................................. 012

293

Sin encontrar el autor de este título concreto, pudieran Luis Martínez -'Principio del Reino de Aragón"' 1581-o Jerónimo Martínez -Discurso del Oficio del Baile General de Aragón, 1630 - ser autores de la misma, por ocuparse de temas aragoneses.

\section{4}

MIGUEL DE MOLINO. Fue elogiado desde su aparición este repertorio foral aragonés, que aún hoy, indica Alonso y Lamban, "es libro imprescindible para quien desee estudiar derecho aragonés: se sirve del derecho romano para construir el derecho propio, utilizando las fuentes más antiguas, y con su ayuda inicia a veces la investigación histórica. "Fue glosado posteriormente por Blancas y Portolés. REPERTORIUM FORORUM ET OBSERVATIARUM REGNI ARAGONUM... Impressum Cesaraugusta Georgig Coci Theutonici, 1513, fol. got. 6 h. con 3 grab. (B.N. Madrid; B.U. Zaragoza). Además de esta $1^{\underline{a}}$ edición se hicieron en f1517, 1519, 1525, $1533,1554,1585,1587,1589$ y 1590. La única edición con el título en castellano es la de 1517, aunque está encabezada por "fueros y desavenencias..." y no por "Repertorio..."' como en algunos casos, puede ser ésta la edición, y el autor del inventario, por conocimiento, dar el nombre latino más conocido, castellanizado ante la obra en castellano.

Ref.: PALAU, t. IX, p. 498, $\mathrm{n}^{\circ}$ 175060; N. ANTONIO, t. II, p. 142; PEREZ MARTIN, p. 317. ALONSO Y LAMBAN, p. 635.

JUAN DE LA RIPIA. vid. $\mathrm{n}^{\circ} 178$.

305

JOSE RAMON: CONSILIORUM UNA CUM SENTENTIIS ET DECISIONIBUS AUDIENTIAE REGIAE PRINCIPATUS CATHALONIAE. Barcinonae, Estenan Libreros, 1628, fol. 1140 p. Barcinonae Typis Bartholormaei Reccaldini, 1689.

Barcinonae, 1695, fol.

Ref.: PALAU, t. XV, p. 85; PEREZ MARTIN, p. 319.

JOSE DE SESSE Y PINOL ( -1629). TRACTATUS DE INHIBITIONIBUS 
ES EXECUTIONE PRIVILEGIATA ET QUARINTIVIGIA FACIENDA, AC EADEM INVIUM EXCEPTIONUM, SEU JURISFIRMAE RETARDENDAE AGETUR ATRIUSQUE IURIS RESOLUTIONES PRACTICAE CUM TOTIDEM DECISSIONIBUS, NECNON CONSUETUDINES REGNI ARAGONUM. Caesaraugusta, 1610, Joan Larumbe, 4, 1615.

- Ioannem Lanaja, 4ํ, 40 fols. 643 p.; 1627 Ioannis Larumbe. P. Martín señala una edición del t. V, en 1608 y desconoce el resto.

- Id. y las ediciones de Barcinonae, Gabriellis Graells, 1608-1618, y otras sin Typ de 1606, 1609, 1615, 1661.

Ref.: PALAU, t. XXI, p. 128, núms. 311104, 311105 , 311106; PEREZ MARTIN, p. 319: ESPASA, t. 47, p. 697; ALONSO Y LAMBAN, p. 635.

\section{Asiento}

\begin{tabular}{|c|c|c|}
\hline 344 & 2 Mayorazgos . & \\
\hline 345 & Alegaciones eclesiásticas $1^{Q}, 2^{Q}$ y $3^{\underline{Q}}$ & \\
\hline 346 & Mayorazgos de la Casa de Urrea ..... & \\
\hline 350 & Alegaciones de los Estados del Marquesado de Villena .......................... & 010 \\
\hline 353 & 2 Vandos y Pragmaticas de Valencia y otras cosas; Manuscriptos ... & 020 \\
\hline 354 & 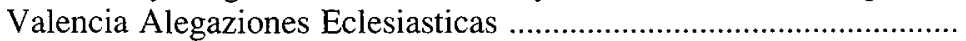 & 008 \\
\hline 355 & 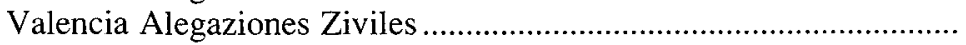 & 010 \\
\hline 356 & 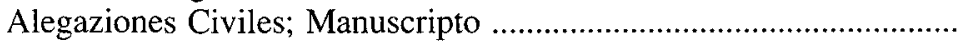 & 008 \\
\hline 358 & Alegaziones Seculares .................... & 008 \\
\hline 359 & Alegaziones Diversas Ziviles; Manuscripto & 008 \\
\hline 360 & Alegaziones Civiles y Canonicas ........................ & 008 \\
\hline 361 & 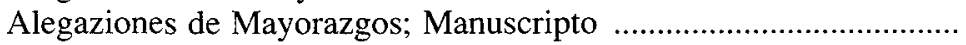 & 008 \\
\hline 362 & Alegaziones Varias & 6 \\
\hline 363 & Alegaziones de Mayorazgos & 006 \\
\hline 364 & Alegaziones utriusque Iuris & 006 \\
\hline 36. & 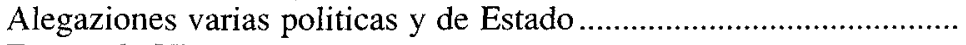 & 006 \\
\hline & ueros de Vizcaya & \\
\hline
\end{tabular}

FUEROS DE VIZCAYA. EL FUERO. PRIVILEGIOS, FRANQUEZAS Y LIBERTADES DE LOS CAVALLEROS HIJOSDALGO DEL SEÑORIO DE VIZCAYA, CONFIRMADOS POR EL EMPERADOR Y REY NUESTRO SEÑOR Y DE LOS REYES SUS PREDECESORES. Medina del Campo, Francisco del Canto. A costa del Señorío de Vizcaya, por orden de Antonio de Zavalla, vizcaíno vezino de Medina del Campo 1575, fol. 116 fols. (ocho primeros sin numerar).

Esta edición segunda tras la de 1528 de Burgos, es la única edición de Medina. Ref.: PALAU, t. V, nº 9563409; GIL AYUSO, núms. 49-340, 341-1136.

\section{Asiento}

366 Alegaziones de Mayorazgos ……………….......................... 008

367 Alegaziones Manuscriptas ………………….......................... 006 
369 Sumario de los Fructos y Rentas de Zaragoza ........................... 006

370 Actas de Cortes del Reyno de Aragón ...................................... 006

374 Casanate de inmunitate. Sin principio ni fin ......................... 004

375 Exea: Discursos históricos y políticos ...................................... 006

376 Consejos de Suelves en Zaragoza ......................................... 010

381 Quadernos y los más tratan de los fueros de Aragón .............. 096

382 Historia de San Juan de la Peña en Zaragoza ......................... 012

\section{4}

LUIS DE CASANATE: DE INMUNITATE GABELLAE PRO NOBILI FIDELISSIMA URBE MESSANA. Aunque los "Consejos" de este aragonés fueron la obra más utilizada, este discurso histórico legal, como lo califica N. Antonio fue también muy conocido.

Ref.: PALAU, t. III, p. 241, n² 46786; ESPASA, t. 12, p. 180; N. ANTONIO, t. I, p. 28.

\section{5}

LUIS DE EJEA Y TALAYERO. Vid. $\mathrm{n}^{\mathrm{0}} 228$. Aunque creemos que este asiento incluye no sólo los "Discursos históricos jurídicos" del n 228, sino también alguna otra obra, aquí calificada como "política" y puede referirse al BREVE DISCURSIO AD INTELIGENTIAM FORORUM ARAGONIAE DE COENIS, o al "Pro juristicione Regii Quaestore Tuenda".

Ref.: PALAU, t. V, p. 28; N. ANTONIO, t. II, p. 33; SIMON, t. IX, p. 533, $n^{0}$ 4310; ESPASA, t. 19, p. 395.

JUAN CRISTOBAL SUELVES, como Portolés o Ramírez, integra Suelves el escaso grupo de juristas aragoneses, que con obras específicamente jurídicas no tratan del tema foral: CONSILIORUM DECISSIONORUM CENTURIA PRIMA. Cesaraugusta ex Petri Verges, 1641, 4 8 h. 228 fols. 13 h.; y también 16426 h. 138 fols.; y 1646, Pedro Lanaja, 6 h. 271 p. (B.N. Madrid). N. Antonio da ligeramente cambiado el título CONSILIORUM SEMICENTUTIAM, Cesaraugusta, 1642.

Ref: PALAU, t. XXII, p. 291, n 324805; N. ANTONIO, t. I, p. 678; ESPASA. t. 58, p. 472 .

381

Este es uno de los asientos globales a que hacíamos referencia en nuestro comentario, significativo por su imprecisión y riqueza de contenido.

382

JUAN MARTINEZ BRIZ: HISTORIA DE LA FUNDACION Y ANTIGÜEDADES DE SAN JUAN DE LA PEÑA Y DE LOS REYES DE SOBRARBE, ARAGON Y NAVARRA... HASTA QUE SE UNIO EL PRINCIPADO DE CATALUÑA CON EL REINO DE ARAGON. Caragoça Juan de Lanaja y Quartenet, 1620 fol. Para el interés de Macanaz por el tema foral esta fundación, como podemos ver, es especial- 
mente interesante por estar estrechamente vinculada a los orígenes del Reino de Aragón.

Ref.: C.B. MONTESA, p. 166, n² 884.

\section{Asiento}

399 Fori Regni Valentia ............................................................... 020

410 Coronación de los Reyes de Aragón ....................................... 008

425 Inscriptiones Latinas ............................................................. 005

426 Otra Coronación de los Reyes de Aragón ............................... 006

443 Zurita. Enmiendas ................................................................. 003

444 Dormer. Discursos varios ....................................................... 004

472 Portolis de consorcibus ....................................................... 003

399

FORI REGNI VALENTIAE: en Valencia por Diego de Gurmiel, 1515, fol.

FORI REGNI VALENTIAE: Valentia: Arte ac industria experti viri, Ioannis a Mey Flandri sub anno MDXLVIII, fol. 6 h. 261-105 fols. 1 h. (Comprende texto latino-catalán). Indica P. Martín que la fecha de Palau de 1515 puede referirse a la edición llevada a cabo por Pastor de 547-48, ignorando P. Martín si existía esa edición o si se trata de confusión. En ella se recopila el derecho valenciano llevado a cabo por Pastor, aprovechando los trabajos de Juan de Alanya y ayudado por Capdevilla. Están contenidos los Fueros valencianos desde Jaime I hasta las Cortes de 1542, en dos partes: en la $l^{\mathrm{a}}, 152$ títulos, distribuidos en 9 libros; y en la $2^{\mathrm{a}}$, fueros actos de Corte y pragmáticas extravagantes.

Ref.: PALAU, t. V, p. 527, no 95623, cf. 526, nº 95616; P. MARTIN, p. 256.

410

JERONIMO DE BLANCAS: CORONACIONES DE LOS SERENISSIMOS REYES DE ARAGON. CON DOS TRATADOS DEL MODO DE TENER LAS CORTES. Caragoça, Diego Dormer 1641, a costa del Reyno. 4\%. 12 h. 261 f. 16 h. (Arch. Corona de Aragón, Barcelona XXVIII-5-6; British Mus. Londres, 1060 h. 13; Academia Española Madrid S.C.= 5.A.174; B.N. París Ob. 26). (Vid. no 426)

Ref.: PALAU, t. II, p. 264, n² 30151; SIMON, t. VI, p. 501, n² 4485.

425

JERONIMO DE BLANCAS. Sólo conocemos las INSCRIPCIONES LATINAS CON LOS RETRATOS DE LOS REYES DE SOBRARBE, CONDES ANTIGUOS Y REYES DE ARAGON PUESTOS EN LA SALA REAL DE LA DIPUTACION DE ZARAGOZA. Zaragoza, Herederos de Diego Dormer, 1680. 17 h. 532 p. con grabs. $20 \mathrm{~cm}$. (B.N. Madrid, 2.65.401; A. Española Madrid 14-VIII-36; British Mus. Londres, 1060 h. 14). Indica Simón que está como traducción. Se añade esta obra al conjunto del tema foral, del que cualquier tema le sirve como información.

Ref.: SIMON, t. VI, p. 503, nº 4492.

JERONIMO DE BLANCAS. Vid. nº 410. 
JERONIMO ZURITA Y CASTRO (1512-1580). Vid. núms. 146 y 147.

ENMIENDAS Y ADVERTENCIAS A LAS CRONICAS DE LOS REYES DE CASTILLA. Zaragoza, herederos Diego Dormer, 1683, 8, 24 h. 504 p. $21 \mathrm{~cm}$.

Ref.: PALAU, t. XVIII, p. $473, n^{\circ} 381775$.

444

DIEGO JOSE DORMER: Este cronista interino de Aragón, unido familiarmente a los encargados de buena parte de la historiografía aragonesa, fue a su vez autor de obras históricas que sorprenden por su vastísima ilustración. DISCURSOS VARIOS DE HISTORIAS CON MUCHAS ESCRITURAS REALES ANTIGUAS Y NOTAS A ALGUNAS DELLAS. Zaragoza, Herederos de Diego Dormer, 1683, $4^{\circ}$ 6 h. 472 p.

Ref.: PALAU, t. IV, p. 517; B. VALENTINA; ESPASA, t. 18, p. 2032.

472

JERONIMO PORTOLES (1546). También este jurista zaragozano dedicó sus estudios a la legislación foral aragonesa.

TRACTATUS DE CONSORTIBUS EIUSDEM REI FIDEICOMMISSO LEGALI. Caesaraugustae. Laurentij \& Didaci Robles Fratrum. 1583, 4, 4 h. 383 p. 16 h.

Ref.: PALAU, t. XIV, p. 24, n⿳ 233612; N. ANTONIO, t. I, p. 598; ESPASA, t. 46 , p. 663 .

\section{BIBLIOGRAFIA}

\section{ENCICLOPEDIAS}

ENCICLOPEDIA JURIDICA SEIX. Dirigida por Buenaventura Pellisé Prats. Barcelona. Editorial Francisco Seix, S.A. 1982.

ENCICLOPEDIA UNIVERSAL ILUSTRADA EUROPEO-AMERICANA. EspasaCalpe, S.A. Madrid. Barcelona.

ENCYCLOPEDIA BRITANICA. Inc. William Benton Pubbisher. 1943 - 1973. 15 th. edition.

GRAN ENCICLOPEDIA CATALANA. Enciclopedia Catalana, S.A. Barcelona, 1974.

\section{CATALOGOS}

A SORT TITLE CATALOGUE OF SPANISH AND PORTUGUESE BOOKS. In the Library of the British Museum, by V.F. Goldsmith. London, 1974. Inventario General de Manuscritos de la Biblioteca Nacional. Ministerio de Educación Nacional. Madrid, 1965.

CATALOGO COLECTIVO DE OBRAS IMPRESAS EN LOS SIGLOS XVI AL XVIII, existentes en las Bibliotecas españolas. Sección I. Ministerio de Educación y Ciencia. Dirección General de Archivos y Bibliotecas. Madrid, 1972.

CATALOGO DE LA BIBLIOTECA PUBLICA. Universidad de Orihuela. "Fernando de Loaces". Sección Jurisprudencia. 
CATALOGO DE LIBREROS ESPAÑOLES. A. Rodríguez Moñino. Sucesores de J. Sánchez Ocaña. Madrid, 1942.

CATALOGO DOCUMENTAL del Archivo de la Real Sociedad Económica del Pais Valencià, 1776-1876. Francisca Aleixandre Tena. Caja de Ahorros de Valencia, 1978.

CATALOGUE GENERAL des livres imprimés de la Biblioteque National. Auteurs. Paris. Imprimerie Nationale. 1976.

CATALOGUE OF BOOKS PRINTED on the Continent of Europe, 1501-1600. In Cambridge Libraries. Compiled by H.M. Adams. Cambridge, 1976-I-II.

LIBRARY OF CONGRESS CATALOG. Books Subjects Washington 1970-1974. Rowman and Littlefield. Totowa, New Jersey, 1976.

THE BRITISH LIBRARY GENERAL CATALOG of printed books to 1975. B.L.C. to 1975 .

THE NATIONAL UNION CATALOG. Pre 1956, Imprents Mansell 1976.

\section{BIBLIOGRAFIAS Y BIOBIBLIOGRAFIAS}

AGUILAR PIÑAL, Francisco: Bibliografía de autores españoles del siglo XVIII. Consejo Superior de Investigaciones Científicas. Instituto Miguel de Cervantes. Madrid, 1983

ANTONIO NICOLAS: Biblioteca Hispana Nova, I-II. Matriti 1738-88, ed. facsímil. Turín, f1963.

BARRIO MOYA, J. L.- CHACON, A.: La biblioteca y las Colecciones artísticas del Rodense D. Fernando de la Encina, canónigo de la Catedral de Cuenca (1740) Al-basit. Año XII, nº 18. Abril, 1986.

BIBLIOTECAS LIBREROS E IMPRESORES MADRILEÑOS DEL S. XVII POR EL MARQUES DE SALTILLO: Rev. Arch. Biblio. y Mus. Alo 1948, t. IV, p. 255.

CARCEL ORTIZ, Vicente: Obras Impresas del s. XVI en la Biblioteca de Juan de Rivera. 1611. Anales del Seminario de Valencia - 1 . $^{\text {er }}$ Sem. 1966. Año VI - $\mathrm{n}^{\mathrm{o}} 11$. COING, Helmut: Handbuch der Quellen und Literatur der neuren Europäishen Privatrechtsges chichte. München: C.H. Beck'sche Verlagsbuchhandlung, 1982. CORREA CALDERON, Evaristo: Registro de Arbitristas, Economistas y Reformadores Españoles (1500-1936). Fundación Universitaria Española. Alcalá, 93 Madrid, 1981.

DESGRAVES, Louris: Repertoire bibliographique des livres imprimés en France au XVII siècle. 1978 Editions Valentin Koerner - Baden-Baden Bibliotheca Bibliographica Aureliana. t. I - XIII.

SANCHEZ CANTON, F. J.: La librería de Juan de Herrera. Consejo Superior de Investigaciones Científicas. Instituto Diego de Velázquez.

FORI ARAGONUM: Mitterlalterliche Gesetzbücher Europäischer Lander. Topos Verlag-Vaduz Liechtenstein, 1979.

FREIRE LOPEZ, Ana María: Indice bibliográfico de la Colección documental del Fraile. Servicio Histórico Militar. Imprenta Ideal. Madrid, 1983.

FUSTER, Justo Pastor: Biblioteca Valenciana de los escritores que florecieron hasta 
nuestros días con imprenta y librería de IIdefonso I-II. Valencia.

GALLARDO BARTOLOME, José: Ensayo de una Biblioteca Española de libros raros y curiosos. Madrid, 1863-89. Editorial Gredos. Biblioteca Románica Hispánica. Madrid, 1968.

HEERMANS, Gerard: Novus Thesaurus iuris civilis et canonicis, continens varia et rarissima optimorum interpretum... opera... tam edita antebao quam ineditum. Haqae Comitum, $1751-1780$.

HUARTE MORTON, Fernando: Las bibliotecas particulares españolas de la Edad Moderna. Rev. Arch. Bibli. y Mus. LXI, 2. 1955.

ENTRAMBASAGUAS, J. de: La biblioteca de Ramírez de Prado, I-II Consejo Superior de Investigaciones Científicas. Imprenta Soler. Bernardino Obregón, 14 Madrid, 1943.

LASPERAS, Jean Michel: La librería del Dr. Juan de Vergara. Rev. Arch. Bibli, y Mus. Madrid LXXIX. 1976, n² 2 - Ab. Jun.

MANZI, Pietro: La Tipografía Napolitana. nel '500. Biblioteca de Bibliografía Italiana. Firenze. Leo S. Olschki Editore. 1971.

MARQUES DE SALTILLO: La biblioteca del Protonotario Agustín de Villanueva. Bibliotecas, Libreros, Impresores. R.A.B. M., t. 54. 1948.

MATEU IBARS, Josefina: La librería de la Orden de Montesa en el siglo XVIII. Consejo Superior de Investigaciones Científicas. Instituto Miguel de Cervantes. Madrid, 1974.

MENDOZA DIAZ, Francisco y GARCIA-SAUCO, L. G.: Dos bibliotecas chinchillanas del siglo XVII. C.S.I.C. Confederación Española de Centros de Estudios Locales. Instituto de Estudios Albacetenses. Albacete, 1983. $n^{2} 6$.

MUÑOZ Y ROMERO T.: Colección de Fueros Municipales y Cartas Pueblas de los Reinos de Castilla, León, Corona de Aragón y Navarra coordinada y anotada. Madrid, 1847. Imprenta de José María Alonso, editor.

PALAU Y DULCET, Antonio: Manual del Librero Hispano-americano $2^{\mathrm{a}}$ edic. Barcelona, 1948.

PAZ Y MELIDA A. y J. SAN PELAYO: La Biblioteca del Conde de Haro. Año 1897, t. I-II; Año 1903, t. VIII-IX. Revist. Arch. Bibli. y Mus.

PEREZ PASTOR, Cristóbal: Bibliografía Madrileña o descripción de las obras impresas en Madrid (siglo XVI). Madrid, 1891.

PESET, Mariano: Notas sobre la abolición de los Fueros de Valencia. A.H.D.E.T. XLII.

REVISTA DE ARCHIVOS, BIBLIOTECAS Y MUSEOS. T. I-XXIX: Madrid. Tipografía de la Revista de Archivos, Bibliotecas y Museos. Propiedad de D. José Manuel de la Cuesta. Infantas 42. 1909.

RODRIGUEZ DE LA TORRE, Fernando: La biblioteca astronómica del Doctor Pedro Gómez de Almodóvar. (Chinchilla, 1667). C.S.I.C. Albasit. Abril, 1985. nº 16.

RODRIGUEZ, Joseph: Biblioteca Valentina. Impresor Joseph Tomas Lucas. Valencia, 1748. Se hallará en la Sacristía del Real Convento del Remedio de esta Ciudad.

ROMEU ALFARO, Sylvia: Los Fueros deValencia y los Fueros de Aragón. A.H.D.E., t. XIII.

SAEZ VIDAL, Joaquín: Inventario de la biblioteca de D. Nicolás Pro, Ilustrado Ali- 
cantino del siglo XVIII. Anales de la Universidad de Alicante. Departamento de Historia Moderna. $\mathrm{n}^{2}$ 2. 1982.

SAINZ RODRIGUEZ, Pedro: Biblioteca Bibliográfica Hispana. Fundación Universitaria Española. Seminario M. Pelayo. Madrid, 1976. I-III.

SAN VICENTE PINO, Angel: Colección de Fuentes de Derecho Municipal aragoneses. A.H.D.E., t. XXIII.

SANCHEZ CANTON: La biblioteca del Marqués del Cenete, iniciada por el Cardenal Mendoza. Madrid, S. Aguirre impresor, 1942. C.S.I.C.

SANCHEZ CANTON: La librería de Juan de Herrera. Instituto Diego Velázquez. Madrid, 1941.

SIMON DIAZ, José: Impresos del siglo XVII. Consejo Superior de Investigaciones Científicas. Instituto Miguel de Cervantes. Madrid, 1972.

TORRES CAMPOS, Manuel: Nociones de bibliográfica y Literatura Jurídica de España. Madrid. Imprenta de Ancha de San Bernardo. 1884.

VOLTES, Pedro: Felipe V y los fueros de la Corona de Aragón. Revista de Estudios Políticos. 1955.

XIMENO, Vicente: Escritores del Reino de Valencia, cronológicamente ordenados desde el año $1238 \ldots$ hasta el año 1747. I-II. Valencia, 1747-49.

\section{INDICE DE AUTORES}

ABELlAN, José Luis: Historia Crítica del Pensamiento Español. Editorial EspasaCalpe. Madrid, 1979.

ALONSO Y LAMBAN, M.: Apuntes sobre juristas aragoneses de los siglos XVI y XVII. A.H.D.E. Madrid, 1963. T. XXIII.

CHEVALIER, Maxime: Lectura y Lectores en la España del siglo XVI y XVII. Ediciones Turner. Madrid, 1976.

DOMINGUEZ ORTIZ, Antonio: La sociedad española en el siglo XVIII. I - Madrid. C.S.I.C. 1963.

DOMINGUEZ ORTIZ, Antonio: Sociedad y Estado en el siglo XVIII español. Editorial Ariel, S.A. Barcelona, 1984.

FAYARD, Janine: Los miembros del Consejo de Castilla (1621-1746) Siglo veintiuno editores 1982 y Les membres du Conseil de Castilla à l'epoque moderne (16211746). Gènève. Librarie Droz 1979.

SAVIGNY, F. Carlo de: Storia del Diritto Romano nel Medio Evo. Multigrafica Editrice - Roma, 1972 - I-III.

GARCIA GALLO DE DIEGO, Alfonso: El origen y la evolución del Derecho Artes Gráficas y Ediciones. Madrid, f1984.

GARCIA GALLO DE DIEGO, Alfonso: Curso de Historia del Derecho Español. Madrid, 1950.

MAYANS Y SISCAR, G.: Obras Completas I-IV. Edición preparada por Antonio Mestre Sanchís. Publicaciones del Ayuntamiento de Oliva. Diputación de Valencia, 1985.

GIBERT, Rafael: Historia General del Derecho. Granada 1968. Madrid M. Huerta. 1980. 
KAMEN, Henry: La Guerra de la Sucesión en España, 1700-1715. Ediciones Grijalbo. Barcelona, 1974.

LALINDE ABADIA: Iniciación histórica al Derecho español. Barcelona, 1970.

LALINDE ABADIA, J.: Los Fueros de Aragón. Librería General. Zaragoza.

LAMARCA LANGA: Las bibliotecas privadas en los protocolos notariales. Anales de la Universidad de Alicante. Libros, Libreros y Lectores, 1984.

LOSCHARKER, P.: Europa y el Derecho Romano. Editorial Revista de Derecho Privado. Madrid, 1955.

MACANAZ, Melchor: Pedimento del Fiscal General sobre Abusos. Madrid en la Imprenta Nacional. 1841.

MACANAZ: Obra Escogida. Madrid, 1847. Imprenta Santiago Rojo. Calle de los Jardines.

MALDONADO MACANAZ, J.: Melchor de Macanaz. Testamento Político. Pedimento Fiscal. Ediciones del Instituto de Estudios Políticos. Madrid, 1972.

MARTIN GAITE, C.: Macanaz, otro paciente de la Inquisición. Editorial Taurus. Madrid, 1975.

MESTRE, A. Corrientes Interpretativas actuales de la Ilustración Española. España a finales del siglo XVIII. Ediciones de la Hemeroteca de Tarragona. 1982.

MESTRE, A.: Difusión de la Cultura Española en los Países Bajos. Mayans y el Círculo de Gerardo Meerman. Anales de la Universidad de Alicante. Revista de Historia Moderna.

OLAECHEA, R.: Ignacio de Heredia y su biblioteca. Anales de la Universidad de Alicante. Libros, Libreros y Lectores. 1984.

OLAECHEA, R. Las relaciones hispano-romanas en la segunda mitad del s. XVIII. I-II. Zaragoza, 1969.

PEREZ MARTIN, A. y SCHOLZ, Johannes-Michel: Legislación y Jurisprudencia en la España del Antiguo Régimen. Universidad de Valencia. Secretariado de Publicaciones. Valencia 1978.

PEREZ MARTIN, Antonio: Los Colegios de Doctores de Bolonia y su relación con España. Anuario de Historia del Derecho Español. T-XLVIII. Madrid, 1978, pp. 5-89.

PEREZ PRENDES Y MUÑOZ DE ARRACO, José Manuel: Apuntes de Historia del Derecho Español. Gráficas Menor. 1964.

PEREZ PRENDES Y MUÑOZ DE ARRACO, José Manuel: Curso de Historia del Derecho Español. Parte General. Editorial Parro. Madrid, 1973.

PESET, J. L. y M.: La Universidad española, siglos XVIII y XIX. Despotismo Ilustrado y revolución Liberal. Madrid, 1974.

PRADELLS NADAL: Notas sobre los orígenes de la Biblioteca Nacional. Anales de la Universidad de Alicante. Libros, Libreros y Lectores. 1984.

SEMPERE GUARINOS, J.: Ensayo de una Biblioteca Española de los mejores escritores del Reinado de Carlos III. I-VI. Madrid, 1785-1789. Biblioteca Románica Hispánica. Editorial Gredos. Madrid, 1969.

SEMPERE GUARINOS, J.: Historia del Derecho Español. Imprenta Real. Madrid, 1823.

TOMAS Y VALIENTE, Francisco: Manual de Historia del Derecho Español. Centro de Enseñanza y Publicaciones. Madrid, 1952. 